\title{
Online Laboratories as a Support System for Learning Processes in Engineering
}

\author{
Luis Felipe Zapata Rivera, Ph.D ${ }^{1}$., Maria M. Larrondo-Petrie, Ph.D2. \\ L.F.ZapataRivera@ieee.org ${ }^{1}$, petrie@fau.edu ${ }^{2}$ \\ ${ }^{1,2}$ Computer \& Electrical Engineering \& Computer Sci. Dept., \\ Florida Atlantic University, Boca Raton FL, USA
}

\begin{abstract}
The Latin American and Caribbean Consortium of Engineering Institutions (LACCEI) and The Organization of American States (OAS) Have been working together in hemispheric initiatives such as: Diversity, the role of women in STEM, Technologies for Learning Engineering among others. Online laboratories allow students to perform experiments at any time from any place. Advantages such as low cost, effectivity and efficiency make these systems attractive for schools with a limited budget to invest in lab equipment, generating a possibility for paying/exchange Lab access as a service with other institutions, saving money in terms of personnel, location and energy bills.
\end{abstract}

This research presents the design of a platform to integrate geographically distributed online laboratories, in a system that allow the integration with educational tools. Including collaboration roles, adaptability of interfaces, traceability of each action of the user and giving valuable information to teachers and administrators and the correct feedback to the students.

Keywords: Engineering Education, Online Laboratories, Systems for Learning Engineering, Technological Standards in education.

\section{Introduction}

The concept of "Engineering Education" has been a subject of research during the last decade and has been interpreted and developed from different points of view. One of the approaches to this concept has been from pedagogy, defining it as the best strategies to improve the quality of engineering training.

Another trend in research in this area has to do with the role of technology as a support tool for engineering education processes. Each of these visions has convergence in a common goal that is to support the development of the education in engineering.

Digital Object Identifier (DOI):

http://dx.doi.org/10.18687/LACCEI2019.1.1.550

ISBN: 978-0-9993443-6-1 ISSN: 2414-6390
Online laboratories is a tool that defines the use of the internet to give users access to perform laboratory experiments remotely or virtually, this concept includes topics such as remote laboratories, virtual laboratories, mobile laboratories and hybrid configurations. Online Laboratories have proven to be a good tool to support the development of the practical component during engineering learning processes $[1,2]$.

The Institute of Electrical, Electronic and Related Engineers (IEEE) has been developing in recent years the first standard for the integration online laboratories in education, as well as the Latin American and Caribbean Consortium of Engineering Institutions (LACCEI) together with the Organization of American States (OAS-OAS) have been developing since 2016 a hemispheric collaboration project around the definition of an open network for the integration of different tools, including online laboratories, for the improvement of the quality of engineering education processes.

\section{Trends in Engineering Education}

Engineering Education is a broad area of research that addresses topics such as: resources and tools to support engineering education, design and curriculum restructuring of engineering programs, strategies and methodologies to support the teaching-learning process in the basic areas of engineering. Problems such as the lack of motivation of students to study engineering, high levels of dropout in engineering programs, misalignment between curriculum and evaluation, the big gap between the skills of recent engineers graduates with respect to the needs of the industry that employs them [3], among others. 
In 2012 [4], in the report called "The five major shifts in engineering education". The biggest changes identified in the evolution of engineering education during the last century were:

- A shift from the practical to an analytical approach and engineering science approach.

- A shift towards education based on achievement and accreditation.

- A shift towards the emphasis of engineering design.

- A shift towards the application of research in education, learning and social behavior sciences.

- A shift towards information, computational, communicational technologies in education.

In 2017 [5] a study was carried out in which they classified different theses and dissertations carried out in the area of engineering in education with the objective of determining the most common approaches of these, finding that there is a greater number of works in the which research topics relate to pedagogical and methodological aspects of the engineering education process. While other aspects such as technological support, development of support tools, among others, were classified as less frequent in the study. These findings give indications that more research and practice is required in the generation and integration of technological tools that support engineering education processes.

\section{Online Laboratories}

Online Laboratories are defined as a technology that allows laboratory experiments to be accessed through a network. These experiments can be remote or virtual laboratories. In the case of remote experiments, the user accesses through a computer interface to control a real laboratory equipment located in a remote location, in the case of virtual experiments the user accesses a virtual environment where he/she will find laboratory settings simulated by computer programs.

Online laboratories are implemented in diverse topics that include areas such as: physics, chemistry, digital circuits, control systems, programming, among others. Elements manipulated in remote experiments include sensors, actuators and controllers configured to be remotely manipulated and generally these include the use of cameras to monitor the experiment during its use. In the case of virtual laboratories, digital versions of these experiments are included through the support of programming languages and web interfaces that allow a realistic visualization of the experiments.

This technology has been used by medical industry, science research and laboratories used in education. During the online experimentation it is very important to monitor and report in real time the data generated during the experimentation processes, information about the user laboratory sessions, the activities performed, information of the experiments as usage statistics, results and status of the equipment, among others.

The definition and implementation of more ways to support these monitoring and traceability processes can generate more robust, reliable, interoperable online laboratory systems adapted to the needs of the users, also allowing the generation of learning analytics [6].

The following figure shows a classification of laboratories according to their type and location.

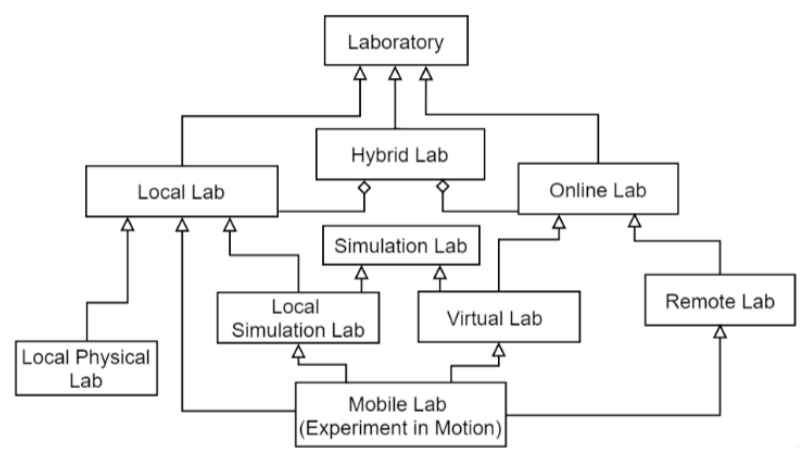

Figure 1. Taxonomy of Laboratories. Adapted from [7]

\section{Online Laboratory Systems Architectures}

Online laboratory systems can have a centralized or distributed architecture. An online laboratory system with a centralized architecture is connected to a central server and can be managed 
from an Online Laboratory Management System (OLMS), in the specific case of remote laboratories, this component is known as the Remote Laboratory Management System (RLMS) [8]. The distributed or decentralized architectures of online laboratory systems propose the definition of each node as independent and self-contained, offering its own access mode and offering the services to the user directly without having to be connected to a centralized server or RLMS.

Other important elements to consider $\mathrm{n}$ online laboratory architectures are mobility and hybrid configurations in which the user performs part of the online experiments and part of the local management. Figure 2 shows a hybrid scheme in which the user performs the experiment locally from a low-cost laboratory kit and complements his experience using the online laboratory system.

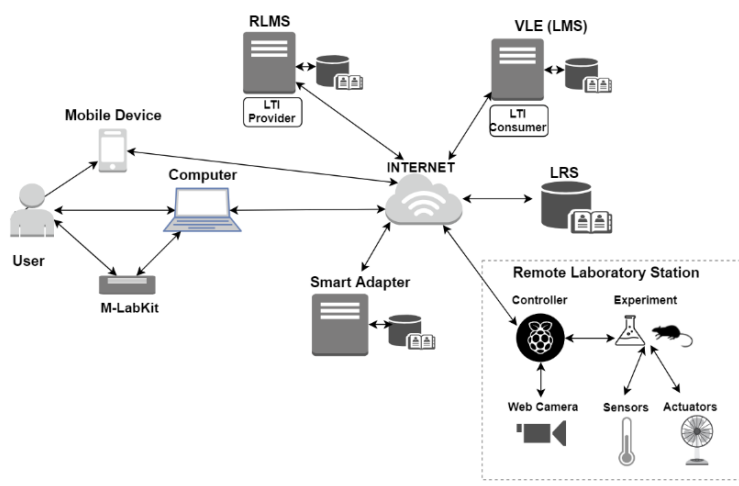

Figure 2. Hybrid laboratory configuration [9]

\section{Development of the IEEE P1876 Standard - Networked Smart Learning Objects for Online Laboratories}

IEEE has been developing in recent years the first standard for the integration and integration of online laboratories in education (Networked Smart Learning Objects for Online Laboratories) [10], This defines the detailed architecture for the implementation and integration of laboratory systems with virtual learning environments (VLE). This standard has been released in June of 2019. The model proposed by the standard defines a layered architecture ranging from hardware to users. See Figure 3.

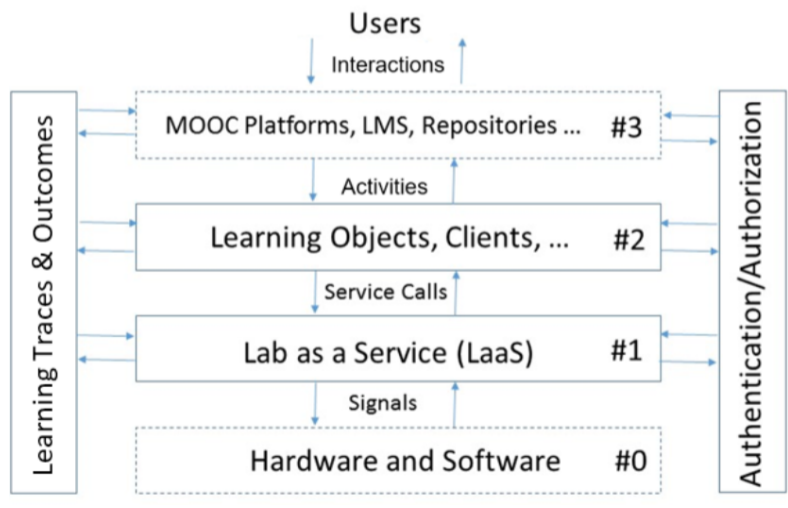

Figure 3. IEEE 1876 architecture layers, Adapted from [11]

\section{Implementation of laboratory integration in line with educational systems}

In 2016 [11] authors proposed an online laboratory system which adapts the set of laboratory activities for the student. In this way different versions and types of activities are integrated into the same remote experimentation equipment, or an activity that makes use of 1 or more distributed laboratory equipment can be defined, giving the user the feeling of having all the tools available in one same place.

The support of this type of interactions requires the definition of a standard laboratory learning object system (Laboratory Learning Object LLO) [12], which encapsulates the configuration of access to remote equipment or simulations, the activities proposed by the teacher and the evaluation schemes. This package can be integrated into an RLMS or a VLE-LMS to be deployed and used by users.

Communications support is given through xAPI allowing all the information generated during the interaction to be captured and collected in the Learning Record Store (LRS). 


\section{Proposal for a network of Laboratories in the Americas}

Some regions of the American continent do not have a good laboratory infrastructure for education. This is a problem that affects the education of millions of students in middle and higher education levels.

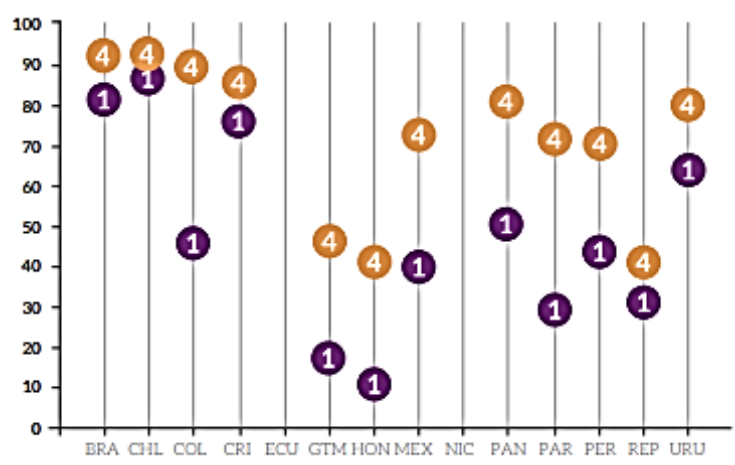

Figure 4. Report of percentage of students with access to equipped classrooms [13]

Online laboratories are an alternative that offers at a very low cost, the possibility of providing the core science and engineering classes practical component, which is important to complete the student learning process. According to UNESCO in its report "Sufficiency, equity and effectiveness of school infrastructure in Latin America according to TERCE" [13] school infrastructure for basic and medium levels is classified as insufficient, within this infrastructure are classified the Science labs This report found that, for example, in countries such as Colombia, Honduras, Guatemala, Mexico, Paraguay, Peru and the Dominican Republic, less than half of the students in the quarter of the poorest students access schools with basic equipment infrastructure in the classroom.

In collaboration between LACCEI and OAS, and through meetings held within the framework of the engineering summit for the Americas during the last 3 years during the LACCEI international education and technology engineering multiconference, has been proposed an initiative for the promotion and motivation of the use of online laboratories in the Americas.
The first achievements of this proposal have been the generation of a research group in the area led by Florida Atlantic University in the United States and with the participation of postgraduate and undergraduate students from the United States, Colombia, Brazil, Peru, Canada and Haiti.

This group has generated the first prototypes of online laboratories used as proof of concept by the IEEE working group P1876. Figure 5, 6, 7 shows some of the demos implemented at Florida Atlantic University.

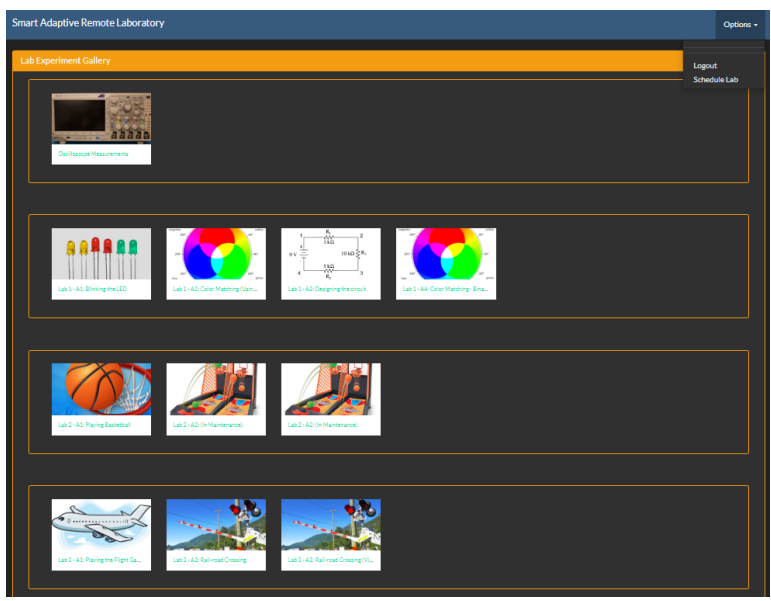

Figure 5. Student interface in the online laboratory system

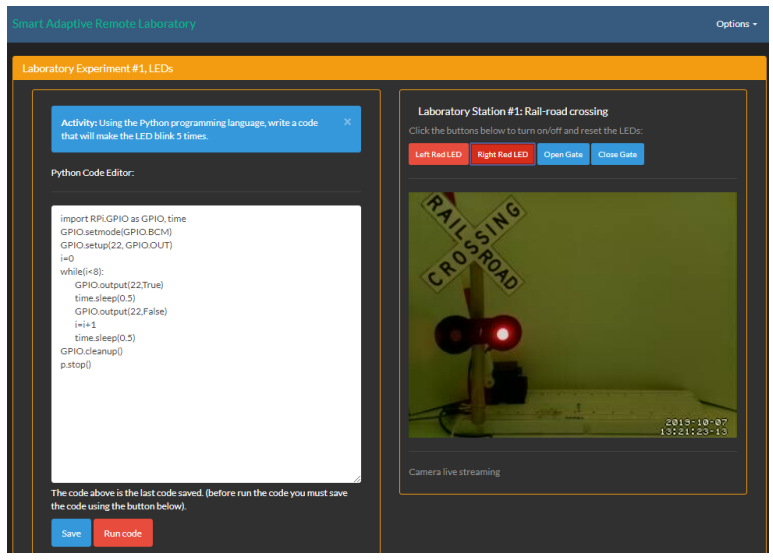

Figure 6. Student interface to use the demo of a remote laboratory to control a traffic light. 


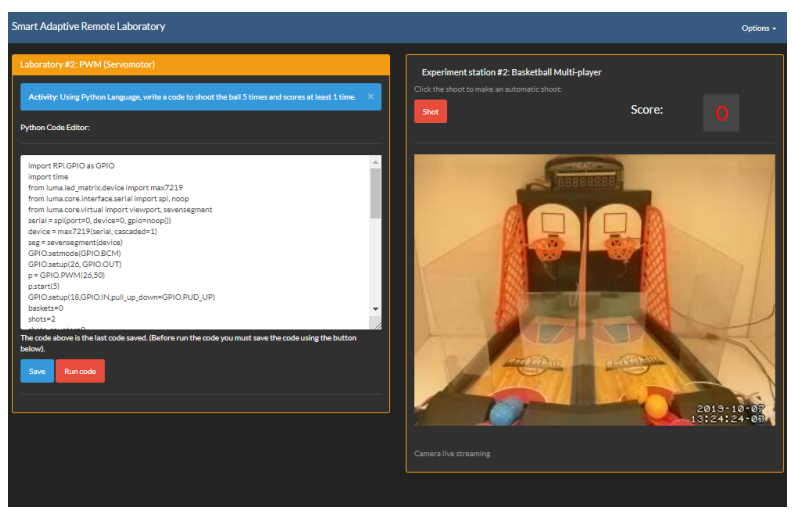

Figure 7. Student interface to use the demo of a remote laboratory to control a basketball game through the use of servo motors and contact sensors

\section{Conclusions and Future Works}

The development of technological tools of easy implementation and low cost that support the learning processes in STEM areas, can benefit to the social development of vulnerable regions of our American continent.

The work carried out has generated the interest of industries and research groups around the world with which collaboration mechanisms can be established for the future and generate project for the establishment of possible joint projects in the area of online laboratories.

\section{References}

[1] Herring Geor K., Neustock L. T., Hesselink L., "Learning from the Unexpected: Statistics and Uncertainty in Massively Scalable Online Laboratories (MSOL)" DOI: 10.1109/EDUCON.2018.8363315, Global Engineering Education Conference (EDUCON), IEEE 2018

[2] Nickerson, J. V., et al. "A model for evaluating the effectiveness of remote engineering laboratories and simulations in education." Computers \& Education 49.3 (2007): 708-725.

[3] Arlett, C., Lamb, F. Dales, R., Willis, L., Hurdle, E. "Meeting the needs of industry: the drivers for change in engineering education" doi: 10.11120/ened.2010.05020018, Routledge, 2015

[4] Froyd, J., Wankat, P., Smith, K., "Five Major Shifts in 100 Years of Engineering Education", DOI: 10.1109/JPROC.2012.2190167, Publisher: IEEE 2012

[5] Zapata Rivera L.F., Larrondo Petrie, M. M., "An Initial Study Applying Data Analysis and Machine Learning Techniques to Analyze Dissertations and Theses in the Engineering Education Field", DOI: 10.1109/JPROC.2012.2190167, Publisher: ASEE 2017

[6] Zapata Rivera, L.F., Larrondo Petrie, M. M., "xAPI-Based Model for Tracking On-line Laboratory Applications" Frontiers in Education (FIE), IEEE 2018

[7] Zapata Rivera, L.F., Larrondo-Petrie, M. M. "Models of Remote Laboratories and Collaborative Roles for Learning Environments ". 11th international Conference on Remote Engineering and Virtual Instrumentation (REV), 2016.

[8] Zutin D. G., Auer M., Orduna P., Kreiter C., and others, "Online lab infrastructure as a service: A new paradigm to simplify the development and deployment of online labs," 13th International Conference on Remote Engineering and Virtual Instrumentation (REV). IEEE, 2016

[9] Zapata Rivera, L.F., Nguyen, T., Huynh V., Kveton, G., Koester, L., Larrondo Petrie M. M., "Implementation of a Student Lab Kit Case to Allow Interfacing with Online Laboratory Systems" Proceedings of the 16th LACCEI International Multi-Conference for Engineering Education and Technology (LACCEI) \}, 2018.

[10] P1876 Working Group (Online): http://sites.ieee.org/sagroups-edusc/

[11] Zapata Rivera, L.F., Larrondo-Petrie, M. M. Implementation of Cloud-Based Smart Adaptive Remote Laboratories for Education. Frontiers in Education (FIE), IEEE 2017

[12] Suficiencia, equidad y efectividad de la infraestructura escolar en América Latina según el TERCE online: http://unesdoc.unesco.org/images/0024/002475/24 7571s.pdf, 2017 